\title{
Establishment of a Mass Screening Method of Sand Fly Vectors for Leishmania Infection by Molecular Biological Methods
}

\author{
Hirotomo Kato,* Hiroshi Uezato, Eduardo A. Gomez, Yoshimi Terayama, Manuel Calvopiña, Hiroyuki Iwata, and \\ Yoshihisa Hashiguchi \\ Department of Veterinary Hygiene, Faculty of Agriculture, Yamaguchi University, Yamaguchi, Japan; Department of Dermatology, \\ Faculty of Medicine, University of the Ryukyus, Okinawa, Japan; Department of Epidemiology and Parasitology, National Institute \\ of Health and Tropical Medicine and Department of Tropical Medicine, Catholic University, Guayaquil, Ecuador; Department of \\ Parasitology, Kochi Medical School, Kochi University, Kochi, Japan
}

\begin{abstract}
Surveillance of the prevalence of Leishmania and its vector, sand fly species, in endemic and surrounding areas is important for prediction of the risk and expansion of leishmaniasis. In this study, a method for the mass screening of sand flies for Leishmania infection was established. This method was applied to 319 field-captured specimens, and 5 positive sand flies were detected. Sand fly species were identified by polymerase chain reaction (PCR)-restriction fragment length polymorphism (RFLP) of the18S rRNA gene, and all the positive flies were Lu. hartmanni. Furthermore, cytochrome $b(C y t$ b) gene sequence analyses identified all the parasites as Endotrypanum species including a probable novel species. Because the method requires minimum effort and can process a large number of samples at once, it will be a powerful tool for studying the epidemiology of leishmaniasis.
\end{abstract}

\section{INTRODUCTION}

Leishmaniasis is a protozoan disease caused by the genus Leishmania. It is distributed worldwide, especially in tropical and subtropical areas, and affects at least 12 million people. More than 20 species of Leishmania are described as causative of human leishmaniases, and clinical features are largely associated with the species. ${ }^{1,2}$ Thus, identification of the parasite species in endemic areas is important for both appropriate treatment and estimation of the prognosis. Female phlebotomine sand flies of the genus Phlebotomus in the Old World and Lutzomyia in the New World are the vectors of Leishmania protozoa. ${ }^{3}$ The spread of leishmaniases depends on the distribution of the vectors and reservoir animals. Nearly 1,000 sand fly species has been described, but only a few are medically important. ${ }^{3}$ In addition, it has been suggested that only a restricted number of sand fly species can support the development of specific species of Leishmania and consequently transmit them. Thus, the detection of Leishmania species within sand flies and identification of both Leishmania and sand fly species is important for prediction of the risk and expansion of the disease in endemic and surrounding areas.

The infection of sand flies with Leishmania promastigotes has usually been examined by dissecting individual sand flies under a microscope. The sand flies should be fresh, and considerable skill and expertise is needed for the study of tiny individuals. Although the procedure takes a relatively long time, a large number of specimens have to be examined to obtain informative data for each area, because the rate of infection of sand flies with Leishmania is generally very low $(0.01-1 \%)$, even in endemic areas. ${ }^{4,5}$ Similarly, sand fly species were identified principally based on morphologic characteristics: mainly internal structures, such as the spermatheca, cibarium, and pharynx for females and terminal genitalia for males. This method requires refined storage conditions for samples, a highly skilled technique, and taxonomic expertise.

* Address correspondence to Hirotomo Kato, Department of Veterinary Hygiene, Faculty of Agriculture, Yamaguchi University, 1677-1 Yoshida, Yamaguchi 753-8515, Japan, E-mail: katoh@yamaguchiu.ac.jp
Thus, the development of alternative ways that can process a large number of specimens with limited effort is awaited. Currently, molecular biologic techniques are used for the detection and identification of Leishmania species in sand flies and patient specimens. ${ }^{6-8}$ In our recent study, a method of detecting Leishmania protozoa within naturally infected individual sand flies by polymerase chain reaction (PCR) with minicircle kinetoplast DNA-specific primers was established. ${ }^{9}$ The method is easy and sensitive; however, several steps were needed for the preparation of template DNA samples, and thus improvements were essential for practical use in the mass screening of sand fly vectors.

In this study, a method of mass screening sand fly vectors for Leishmania infection was established. The method was applied to 319 field-captured specimens and its usability was confirmed. In addition, the sand fly species were identified by PCR- restriction fragment length polymorphism (RFLP) of the $18 \mathrm{~S}$ rRNA gene using the same specimens. The method requires minimum effort and thus will be a powerful tool for research on prevalent sand fly species and the relationships between Leishmania species and the vectors.

\section{MATERIALS AND METHODS}

Parasites. A WHO reference strain of L. (Leishmania) major (MHOM/SU/73/5ASKH) was cultured in RPMI 1640 medium (Nissui Pharmaceutical, Tokyo, Japan) supplemented with $10 \%$ fetal calf serum (FCS; Cansera International, Ontario, Canada), $2 \mathrm{mmol} / \mathrm{L}$ L-glutamine, $100 \mathrm{U} / \mathrm{mL}$ penicillin, and $100 \mu \mathrm{g} / \mathrm{mL}$ streptomycin at $25^{\circ} \mathrm{C}$.

Sand fly collection. Sand flies were collected on August 2006 in endemic areas of Ecuador where cutaneous leishmaniasis caused by L. (Viannia) panamensis and L. (V.) guyanensis is prevalent. ${ }^{4,5,10,11}$ The sites were as follows:

Portoviejo (Province of Manabi): San Sebastian (Province of Manabi) and surrounding areas $\left(1^{\circ} 20^{\prime} \mathrm{S}, 80^{\circ} 05^{\prime} \mathrm{W}\right), \sim 80 \mathrm{~km}$ from Potoviejo city, at an altitude of $600 \mathrm{~m}$. Collections using CDC light traps were made in a banana and cacao plantation.

Piedrero (Province of Cañar): Piedrero $\left(2^{\circ} 50^{\prime} \mathrm{S}, 79^{\circ} 20^{\prime} \mathrm{W}\right)$, $\sim 20 \mathrm{~km}$ from La Troncal city (Province of Cañar), at an 
altitude of $500 \mathrm{~m}$. Collections using CDC light traps were made in a banana and cacao plantation.

Ocaña (Province of Cañar): Ocaña $\left(2^{\circ} 50^{\prime} \mathrm{S}, 79^{\circ} 10^{\prime} \mathrm{W}\right), \sim 5 \mathrm{~km}$ from La Troncal city, at an altitude of $400 \mathrm{~m}$. Collections were made using protected human bait in a subtropical forest.

The sand flies were fixed in $70 \%$ ethanol and stored at room temperature. Ethanol-fixed sand flies experimentally infected with $L$. (L.) major were kindly provided by Dr. Jesus G. Valenzuela (NIH, Rockville, MD).

DNA extraction. For the preparation of parasite DNA, 10,000 parasites were suspended in $50 \mu \mathrm{L}$ of DNA extraction buffer (150 mmol/L NaCl, $10 \mathrm{mmol} / \mathrm{L}$ Tris-HCl [pH 8.0], 10 $\mathrm{mmol} / \mathrm{L}$ EDTA, and $0.1 \%$ sodium dodecyl sulfate [SDS]) in the presence of proteinase $\mathrm{K}(200 \mu \mathrm{g} / \mathrm{mL})$ and serially diluted 10 -fold in the same buffer. For the extraction of DNA from sand flies, ethanol-fixed specimens were placed individually in each well of 96-well plates and lysed in $50 \mu \mathrm{L}$ DNA extraction buffer without homogenization. The samples were incubated at $37^{\circ} \mathrm{C}$ for 12 hours, $25 \mu \mathrm{L}$ distilled water was added, and $0.5-\mu \mathrm{L}$ portions were directly used as the templates for PCR amplification. The DNA samples were stored at $-20^{\circ} \mathrm{C}$ for further use.

Identification of sand fly species. For the identification of sand fly species by PCR-RFLP, PCR amplification was performed with Lutzomyia $18 \mathrm{~S}$ rRNA gene-specific primers. ${ }^{12,13}$ The primer sequences were 5'-TGCCAGTAGTTATATGCTTG-3' (Lu.18S 1S) and 5'-CACCTACGGAAACCTTGTTAC-3' (Lu.18S AR). PCR was carried out in a volume of $20 \mu \mathrm{L}$ using the primers $(0.4 \mu \mathrm{mol} / \mathrm{L}$ each $)$, Ampdirect Plus (Shimadzu Biotech, Tsukuba, Japan), and Taq polymerase (Ex Taq; Takara Bio, Shiga, Japan). After an initial denaturation at $95^{\circ} \mathrm{C}$ for 5 minutes, PCR amplification was performed with 40 cycles of denaturation $\left(95^{\circ} \mathrm{C}, 1\right.$ minute $)$, annealing $\left(50^{\circ} \mathrm{C}, 1\right.$ minute $)$, and polymerization $\left(72^{\circ} \mathrm{C}, 2 \mathrm{~min}-\right.$ utes), followed by a final extension at $72^{\circ} \mathrm{C}$ for 10 minutes.

Each PCR product $(5 \mu \mathrm{L})$ was digested with the restriction enzyme, AfaI (Takara Bio) or HinfI (Takara Bio) in 96-well $\mathrm{V}$-bottom plates. The digested samples were separated by electrophoresis in a $3 \%$ agarose gel to produce DNA fragments.

Detection and identification of Leishmania species. For detection of Leishmania parasites within sand flies, PCR was performed with primers specific for Leishmania minicircle kinetoplast DNA. ${ }^{9}$ The primer sequences were 5'-CTRGGGGTTGGTGTAAAATAG-3' (L.MC-1S) and 5'-TWTGAACGGGRTTTCTG-3' (L.MC-1R). PCR was carried out in a volume of $20 \mu \mathrm{L}$ using the primers $(0.4 \mu \mathrm{mol} / \mathrm{L}$ each $)$, Ampdirect Plus (Shimadzu Biotech), and Taq polymerase (NovaTaq Hot Start DNA Polymerase; Novagen, Darmstadt, Germany). After an initial denaturation at $95^{\circ} \mathrm{C}$ for $10 \mathrm{~min}-$ utes, PCR amplification was performed with 35 cycles of denaturation $\left(95^{\circ} \mathrm{C}, 1\right.$ minute $)$, annealing $\left(55^{\circ} \mathrm{C}, 1\right.$ minute $)$, and polymerization $\left(72^{\circ} \mathrm{C}, 1\right.$ minute), followed by a final extension at $72^{\circ} \mathrm{C}$ for 10 minutes. The PCR products were analyzed on a $2 \%$ agarose gel.

For the identification of Leishmania species using a molecular biologic method, PCR amplification was performed with primers specific for Leishmania $C y t$ b. ${ }^{9,14}$ The primer sequences were 5'-GGTGTAGGTTTTAGTYTAGG-3' (L.cyt-S) and 5'-CTACAATAAACAAATCATAATATR-
CAATT-3' (L.cyt-R). The conditions for PCR amplification were the same as for the Leishmania minicircle kinetoplast DNA. The products were electrophoresed on a $2 \%$ agarose gel and directly cloned into the plasmid using a pGEM-T Easy Vector System (Promega, Madison, WI). Escherichia coli, JM109 cells, were transformed with the ligation mixture and plated onto LB agar containing ampicillin $(50 \mu \mathrm{g} / \mathrm{mL})$, 5-bromo-4-chloro-3-indolyl $\beta$-D-galactoside (X-gal; $36 \mu \mathrm{g} /$ $\mathrm{mL}$ ), and isopropyl $\beta$-D-thiogalactoside (IPTG; $40 \mu \mathrm{g} / \mathrm{mL}$ ). Plasmid DNA was extracted with a QIAprep Spin Miniprep Kit (QIAGEN, Tokyo, Japan). The inserts of the plasmids were sequenced by the dideoxy chain termination method using a BigDye Terminator v3.1 Cycle Sequencing Kit (Applied Biosystems, Foster City, CA).

Phylogenetic analysis. The Leishmania and Endotrypanum $C y t \mathrm{~b}$ gene sequences were aligned with CLUSTAL W software $^{15}$ and examined using the program MEGA (Molecular Evolutionary Genetics Analysis) version 3.1. ${ }^{16}$ Neighborjoining (NJ) trees were constructed with the distance algorisms available in the MEGA package. The database for phylogenetic analyses consisted of $C y t \mathrm{~b}$ gene sequences from six prevalent Leishmania spp., L. (L.) amazonesis, L. (L.) mexicana, L. (L.) major-like, L. (V.) panamensis, L. (V.) braziliensis and L. (V.) guyanensis, in Ecuador and two Endotrypanum spp., E. schaudinni and E. monterogeii.

\section{RESULTS}

Sensitivity and specificity of the PCR. For the detection of Leishmania within sand flies, a pair of primers specific for Leishmania minicircle kinetoplast DNA, which were designed in our recent study, ${ }^{9}$ were applied in this study. However, there are many differences between the previous and present assay: 1) with or without homogenization of individual specimens during the extraction of the DNA, 2) the absence or presence of biologic substances and reagent for DNA extraction in each DNA solution, 3) the final volume of each DNA sample (10 versus $75 \mu \mathrm{L}$ ), and 4) the reagent for PCR amplification. Therefore, the sensitivity and specificity of the primers for the detection of Leishmania were assessed in this assay. As shown in Figure 1, we could amplify minicircle kinetoplast DNA if only one parasite existed in a sample. In the next step, PCR was performed using sand fly samples infected experimentally with Leishmania to test the sensitivity and specificity of the present assay. When amplified with Leishmania minicircle kinetoplast DNA-specific primers, a distinct DNA band of $\sim 700 \mathrm{bp}$ corresponding to minicircle DNA was detected in a Leishmania-positive sand fly sample (Figure 2, lane 3 ) but not in a negative one (Figure 2 , lane 1). On the other hand, a $\sim 2,000$-bp fragment corresponding to the sand fly $18 \mathrm{~S}$ rRNA genes was amplified in both samples (Figure 2, lanes 2 and 4). Thus, target genes were successfully amplified with good specificity and sensitivity, and minimum effort.

Mass screening of sand flies from areas where leishmaniasis is endemic. The newly established method was applied to the mass screening of sand flies from areas where leishmaniasis is endemic. Ethanol-fixed sand fly samples were lysed in DNA extraction buffer without homogenization for 12 hours in 96well plates and directly used as templates for PCR. For the detection of Leishmania, amplification was performed with minicircle DNA-specific primers in 96-well PCR plates, and 


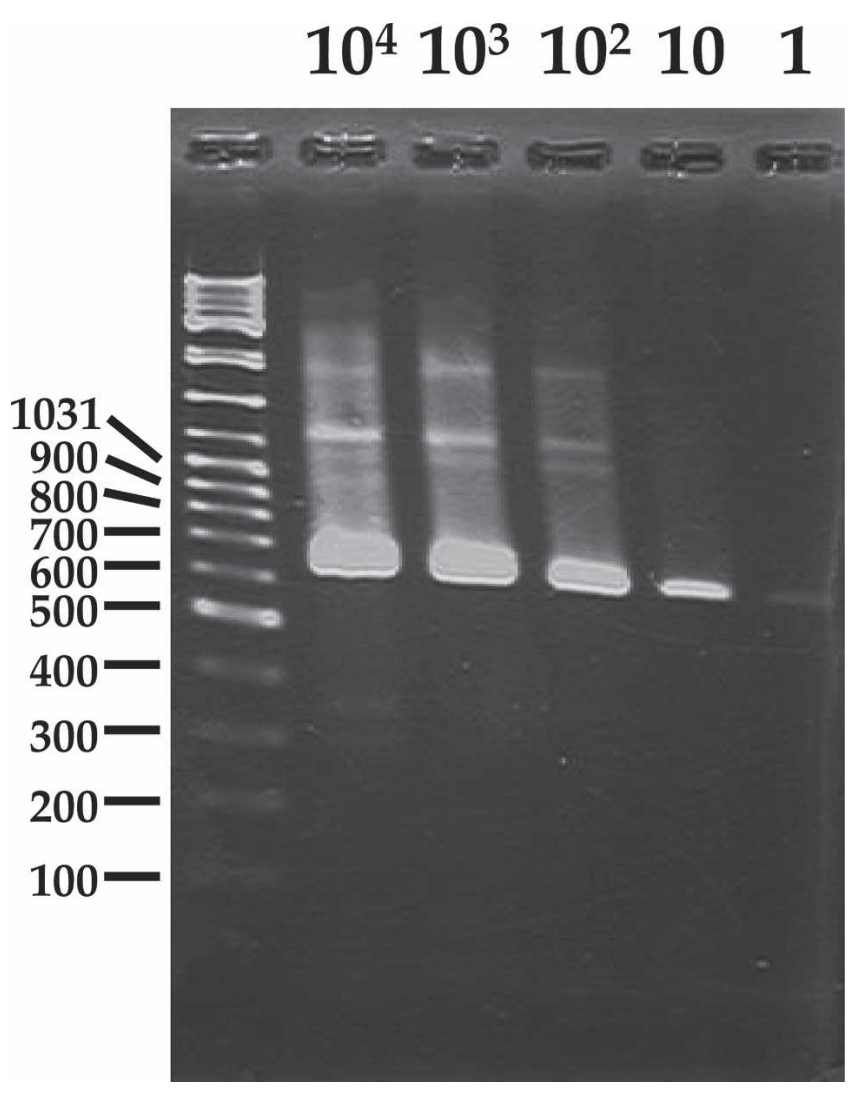

FIGURE 1. Specificity and sensitivity of PCR with primers specific for Leishmania minicircle kinetoplast DNA. Ten thousand parasites were suspended in $50 \mu \mathrm{L}$ DNA extraction buffer and serially diluted 10 -fold in the same buffer. The samples $\left(10^{4}, 10^{3}, 10^{2}, 10\right.$, or 1 parasites) were incubated at $37^{\circ} \mathrm{C}$ for 12 hours, $25 \mu \mathrm{L}$ of distilled water was added, and $0.5-\mu \mathrm{L}$ portions were directly used as the templates for PCR amplification.

the PCR products were analyzed on $2 \%$ agarose gels. Figure 3 shows the results for 96 samples from Piedrero, 2 of which were positive. In this way, 113, 76, and 130 samples from Piedrero, Portoviejo, and Ocaña, respectively, were tested and two, zero, and three positive sand flies, respectively, were detected (Table 1). The sand fly species were also examined by a recently established method using the PCR-RFLP of $18 \mathrm{~S}$ rRNA genes. ${ }^{13}$ PCR amplification was performed with sand fly $18 \mathrm{~S}$ rRNA gene-specific primers using the same samples in 96-well PCR plates and the products were digested with $A f a I$ or HinfI in 96-well plates for typing of the species. Figure 4 shows the results for 16 samples from Piedrero. Lu. hartmanni was identified by digestion with $A f a$ I. Subsequent treatment with HinfI revealed Lu. trapidoi, Lu. gomezi, and Lu. dysponeta in these samples (Figure 4). In this way, all 113, 76, and 130 sand fly species from Piedrero, Portoviejo, and Ocaña, respectively, were successfully classified (Table 1 ). Thus, the distribution of Lu. hartmanni, Lu. trapidoi, Lu. gomezi, Lu. dysponeta, and Lu. serrana from Piedrero and Portoviejo and Lu. hartmanni and Lu. trapidoi from Ocaña was confirmed. The results corresponded to those obtained by the morphologic identification of species in the same sand fly pool conducted during the field research activities. All the minicircle DNA-positive sand flies were identified as Lu. hartmanni.

Analysis of $\boldsymbol{C y t} \mathbf{b}$ genes in the positive samples. To identify the parasite species within the minicircle DNA-positive sand

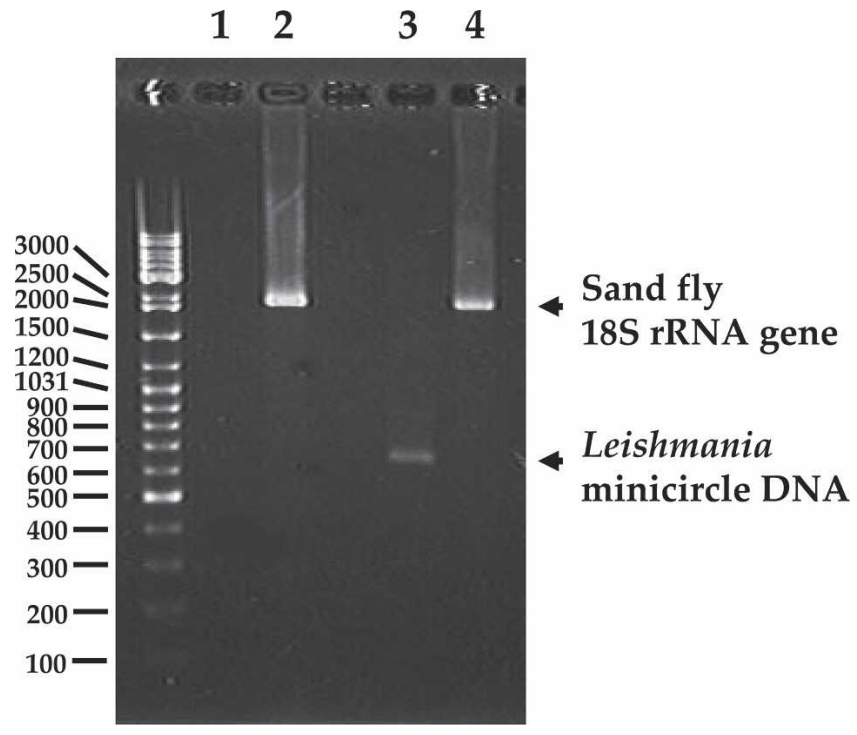

FIGURE 2. Detection of Leishmania minicircle kinetoplast DNA within Leishmania-negative (lane 1) or -positive (lane 3) sand flies by PCR. The Lutzomyia $18 \mathrm{~S}$ rRNA gene was also amplified in these samples (lanes 2 and 4, respectively).

flies, Cyt b was analyzed because the gene has been shown to be good indicator for the classification of Leishmania species. $^{9,14,17,18} C y t$ b genes from four of five positive samples were successfully amplified, and the sequences were determined. The sequences were compared with those from six prevalent Leishmania, L. (L.) amazonesis, L. (L.) mexicana, L. (L.) major-like, L. (V.) panamensis, L. (V.) braziliensis, and L. $(V$.$) guyanensis, in Ecuador and two Endotrypanum$ spp., E. schaudinni and E. monterogeii, both of which had identical $C y t$ b sequences, and all the samples tested had the

\section{M}

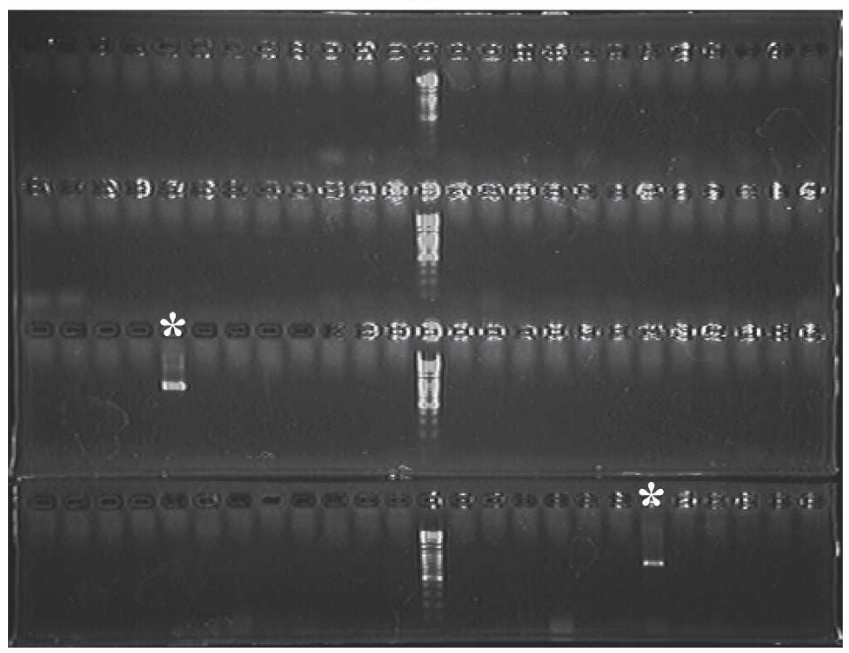

FIGURE 3. Mass screening of sand fly vectors for Leishmania infection. Ethanol-fixed sand fly samples were lysed in DNA extraction buffer without homogenization for 12 hours in 96-well plates and directly used as the templates for PCR with Leishmania minicircle DNA-specific primers. The PCR products were analyzed by electrophoresis on a $2 \%$ agarose gel. The figure shows the results for 96 samples from Piedrero. Asterisks denote minicircle DNA-positive specimens. Lane M, DNA molecular weight marker. 
TABLE 1

Mass screening of sand flies from endemic areas of leishmaniasis in Ecudor

\begin{tabular}{llrrrrrr}
\hline \multicolumn{1}{c}{ Locality } & Captured by & $L u . h$ & $L u . t$ & $L u . g$ & $L u . d$ & Total & Positive \\
\hline Piedrero & CDC trap & 15 & 10 & 78 & 9 & 1 \\
Portoviejo & CDC trap & 6 & 2 & 29 & 36 & 4 \\
Ocaña & Human bait & 113 & 17 & 0 & 0 & 0 \\
\hline
\end{tabular}

Lu. h, Lu. hartmanni; Lu. t, Lu. trapidoi; Lu. g, Lu. gomezi; Lu. d, Lu. dysponeta; Lu. s, Lu. serrana.

highest level of homology with Endotrypanum species (Table 2). A phylogenetic tree was also constructed based on those sequences to see the relationships among species. As shown in Figure 5, all four positive samples divided into the same clade as E. schaudinni and E. monterogeii but not Leishmania species. These results indicated that all the positive sand flies were infected with Endotrypanum species. In the Cyt b gene analysis, one sample (Ocaña 1-12G) had a relatively low level of homology (93.3\%), whereas the other three (Ocaña 1-11B, Piedrero 7E, and Piedrero 12C) were almost identical

\section{A}

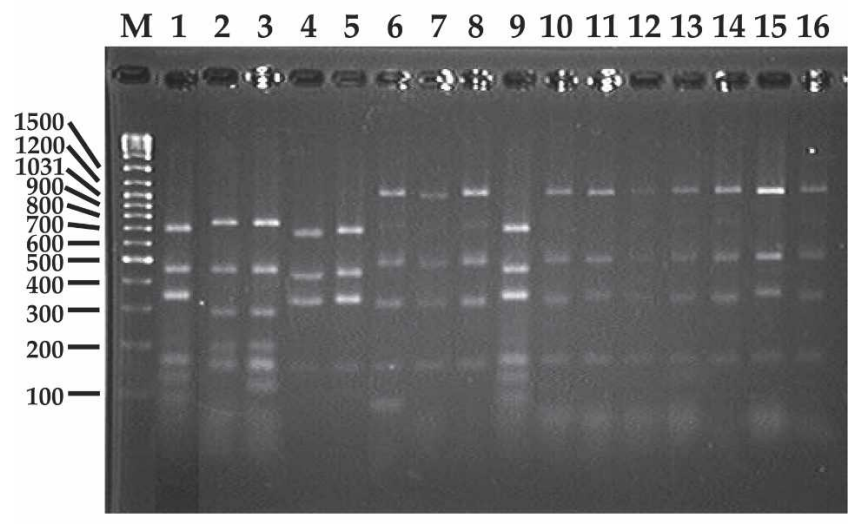

h t t/p t/p h $\quad$ h g/d g/d g/d h $g / d$ g/d g/d g/dg/d g/d g/d

\section{B}

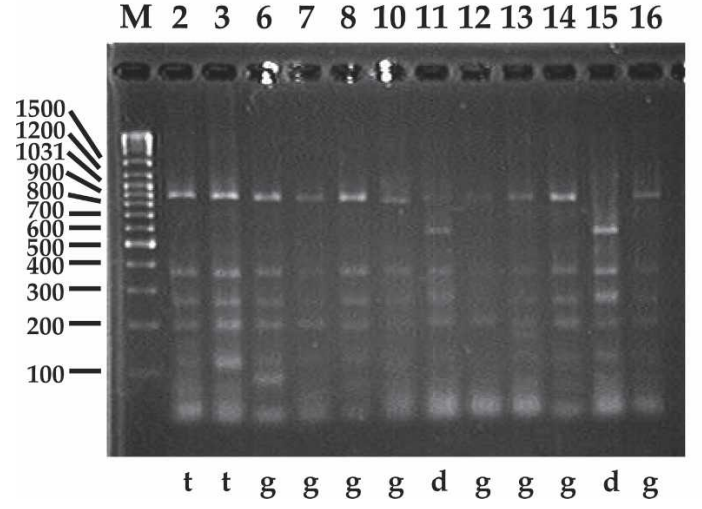

FIGURE 4. Mass screening of sand fly vectors. PCR amplification was performed with sand fly $18 \mathrm{~S}$ rRNA gene-specific primers in 96well PCR plates and the products were digested with AfaI or HinfI in 96-well plates for typing of the species. The figure shows the results for 16 samples from Piedrero digested with $A f a \mathrm{I}$ (A) or HinfI (B). Lane M, DNA molecular weight marker; lanes 1-16, sample numbers. The results of the species identification are shown at the bottom. h, Lu. hartmanni; t, Lu. trapidoi; g, Lu. gomezi; d, Lu. dysponeta; t/p, Lu. trapidoi or Lu. panamensis; g/d, Lu. gomezi or Lu. dysponeta.
(99.6\%) with Endotrypanum species (E. schaudinni and E. monterogeii; Table 2). The phylogenetic analysis also showed that Ocaña 1-12G classified into a separate branch from the other three samples and Endotrypanum species (Figure 5), strongly suggesting that Ocaña $1-12 \mathrm{G}$ belongs to a novel Endotrypanum species.

\section{DISCUSSION}

In this study, a method of mass screening sand flies for Leishmania infection was established. The method was applied to 319 field-captured specimens, and five positive sand flies were detected. In addition, all the species were successfully identified by PCR-RFLP of the $18 \mathrm{~S}$ rRNA gene, and the positive flies were all Lu. hartmanni. Furthermore, Cyt b gene sequence analyses identified the parasites as Endotrypanum species.

Molecular biologic techniques have been applied to the detection and identification of Leishmania species. ${ }^{6-8}$ In our recent study, a method of detecting Leishmania protozoa within naturally infected individual sand flies by PCR with minicircle kinetoplast DNA-specific primers was established. ${ }^{9}$ The method is easy and sensitive; however, some improvements were needed for practical use in the mass screening of sand fly vectors. Therefore, we decided to apply Ampdirect (Shimadzu), a reagent recently produced for genotyping and other purposes, which allows PCR in the presence of inhibitory substances in biologic samples, as well as reagents in DNA extraction buffer. The experimental conditions were successfully optimized and the method was applied to the mass screening of sand fly vectors. The merit of this procedure is that one is able to acquire data on individuals. In some endemic areas, one sand fly species is dominant, ${ }^{9,19}$ and information on circulating Leishmania species and infection rates in the sand fly population can be obtained from pooled samples. ${ }^{19}$ However, several sand fly species co-exist in most areas where leishmaniasis is endemic, and the use of pooled samples is apt to lose some important information on the vector epidemiology such as the prevalent sand fly species as a risk factor and the relationships between Leishmania spe-

TABLE 2

Homologies (\%) of $C y t$ b sequences from minicircle DNA-positive samples with those from reference strains

\begin{tabular}{llccccccc}
\hline Locality & Number & L. $a$ & L.me & L. $p$ & L.g & L. $m-l$ & L. $b$ & E. $s p p$ \\
\hline Piedrero & 7E & 88.5 & 88.6 & 87.4 & 87.0 & 87.3 & 87.5 & 99.6 \\
& 12C & 88.5 & 88.6 & 87.4 & 87.0 & 87.3 & 87.5 & 99.6 \\
Ocaña & 1-11B & 88.5 & 88.6 & 87.4 & 87.0 & 87.3 & 87.5 & 99.6 \\
& 1-12G & 88.9 & 88.4 & 88.2 & 88.0 & 86.5 & 88.6 & 93.3 \\
\hline
\end{tabular}

L. a, L. (L.) amazonesis; L. me, L. (L.) mexicana; L. p, L. (V.) panamensis; L. g, L. $(V$. guyanensis; L. m-l, L. (L.) major-like; L. b, L. (V.) braziliensis; E. spp, Endotrypanum spp. 


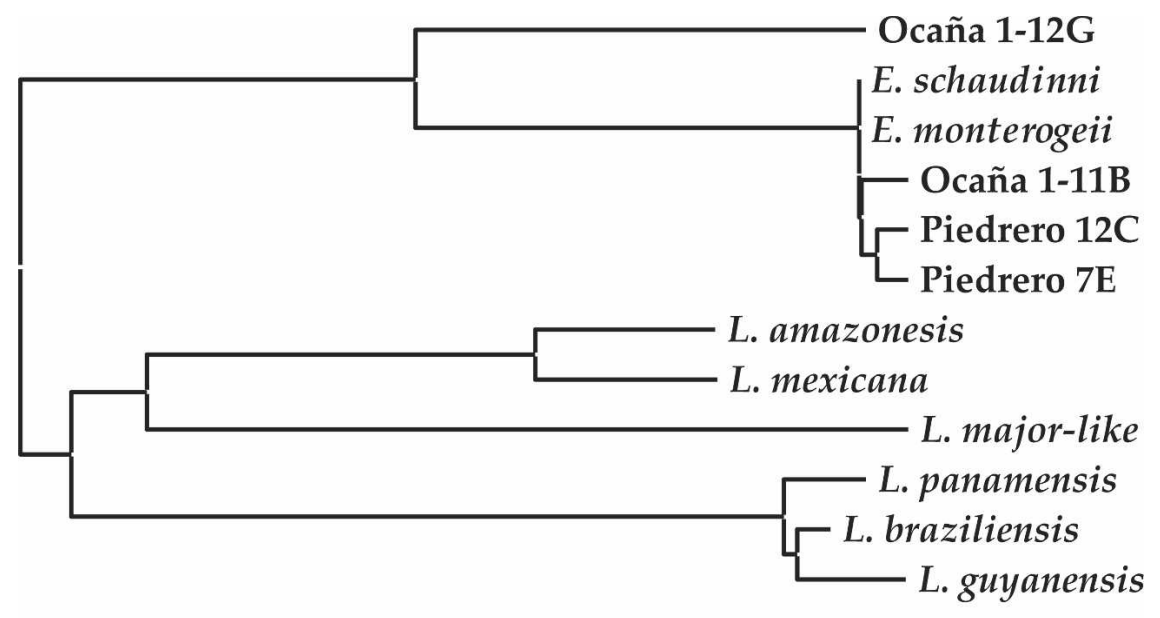

\subsection{1}

Figure 5. Phylogenetic tree of $C y t \mathrm{~b}$ gene sequences among species. The $C y t \mathrm{~b}$ genes of the parasites were amplified from the minicircle DNA-positive sand fly samples (Ocaña 1-12G, Ocaña 1-11B, Piedrero 7E, and Piedrero 12C), and the sequences were determined. Analyses were performed based on the sequences together with those from six prevalent Leishmania species in Ecuador (L. amazonesis, L. mexicana, L. major-like, L. panamensis, L. braziliensis, and L. guyanensis) and two Endotrypanum species (E. schaudinni and E. monterogeii). The scale bar represents $0.01 \%$ divergence.

cies and the vectors. Other advantages of this method are that it minimizes the risk of contamination among samples and loss of DNA during the procedure because of the limited processes for DNA extraction.

In this study, minicircle kinetoplast DNA could be amplified if only one parasite exists in a sample by using $L$. (L.) major as a template. The primers were designed based on sequences conserved among species and confirmed to work on all seven species examined in our recent study. ${ }^{9}$ Thus, the primers were considered to work for all the Leishmania species. In addition, the specificity of the primers was tested using ethanol-fixed L. major-infected sand fly samples and no non-specific band was detected, as observed in a recent study using the same primers. In this study, the PCR-RFLP method $^{13}$ was applied for mass screening using 96 -well plates in each process, and 319 field-captured sand flies were analyzed. As a result, Lu. hartmanni, Lu. trapidoi, Lu. gomezi, $L u$. dysponeta, and Lu. serrana were identified in the three subtropical areas where leishmaniasis is endemic. The results were consistent with our previous data obtained by morphologic identification through long-term epidemiologic research. ${ }^{10}$ Many Lu. dysponeta were identified from Piedrero and Portoviejo, where sand flies were captured with CDC light traps, but not from Ocaña, where sand flies were collected using protected human bait. Lu. dysponeta usually do not bite humans for feeding, and the lack of species in specimens from Ocaña probably resulted from the method of collection used. Thus, sampling methods have to be taken into consideration when studying the epidemiology of sand flies.

The mass screening of vectors from the present three endemic areas resulted in the detection of five minicircle DNApositive sand flies. The five were identified as Endotrypanum species based on Cyt b gene sequencing. Endotrypanum and Leishmania are parasites belonging to the family Trypanosomatidae and are the two most closely related genera. ${ }^{20} \mathrm{En}$ dotrypanum parasites infect the erythrocytes of mammalian hosts, and infections have been reported in sloths and squir- rels but not humans. ${ }^{20,21}$ Both Endotrypanum and Leishmania are transmitted by sand fly vectors, and therefore, the discrimination of these parasites is important for epidemiologic surveillance of reservoir host and sand fly vectors. ${ }^{20}$ In this study, Leishmania parasites were not detected in the mass screening because of the very low infection rate $(0.01-1 \%)$ among sand fly populations, even in the endemic areas. Testing sand fly samples from highly infected populations (1-8\%) in Andean areas in Ecuador using this method should give positive results in a certain number of samples. ${ }^{9}$ Further surveillance of larger populations using the present mass screening will provide more information on each endemic area. Currently, only two named species, E. schaudinni and E. monterogeii, have been described in the genus Endotrypanum, ${ }^{20}$ and both species have identical $C y t$ b sequences (Uezato $\mathrm{H}$ and others, unpublished data). Four of five positive samples were successfully sequenced, and three samples were considered to be E. schaudinni or E. monterogeii on the basis of the Cyt b sequencing analysis. On the other hand, the sequence from the rest, Ocaña 1-12G, had relatively low level of homology with sequences from the above-mentioned three samples, $E$. schaudinni and E. monterogeii. The phylogenetic analysis classified the Ocaña 1-12G into a separate branch from the others, strongly suggesting that the sample belongs to a novel Endotrypanum species. At present, definitive evidence was not given; however, further molecular analyses of other genes may clarify the issue. An attempt to isolate the parasites from sand flies in each PCR-positive area will be necessary. According to a recent study, PCR-RFLP analysis of genes including the small subunit and internal transcribed spacer 1 of rRNA gene can be an effective tool for classification of the main New World Leishmania species. $^{22}$ The method was applied with a slight modification, and Endotrypanum species seemed to have a unique RFLP pattern after AfaI or HapII digestion compared with Leishmania species distributing in Ecuador (Kato $\mathrm{H}$ and others, unpublished data). Thus, Endotrypanum species are probably distinguishable in materials 
from Leishmania species by PCR-RFLP without sequencing of the Cyt b gene.

In conclusion, a method of mass screening sand fly vectors was established for the detection of Leishmania and identification of sand fly species from individual samples. The method requires minimum effort, and therefore will be a powerful tool for studying the epidemiology of leishmaniasis. Use of the method will disclose the prevalent sand fly species as a risk factor and the relationships between Leishmania species and the responsible vectors in a given endemic area.

Received February 13, 2007. Accepted for publication May 1, 2007.

Acknowledgments: We thank Roberto Sud for technical assistance throughout the study; director Dr. Luiggi Martini and the coordinator Dr. Ernesto Gutierrez (NIH and Trop. Med., Ecuador) for arrangement of our field activities; Drs. Teresa Flor, Jenny Rodriguez, and Yim-Yan Wong Chum (NIH and Trop. Med., Ecuador) for support at the laboratory and field phases of the study; Drs. Yuichi Yotsuyanagi and Kenji Ninomiya (Shimadzu Biotech, Tsukuba, Japan) for technical assistance on Ampdirect PCR methods; Dr. Jesus G. Valenzuela (NIH, Bethesda, MD) for providing sand flies experimentally infected with $L$. (L.) major; and The DNA Core facility of the Center for Gene Research, Yamaguchi University, for technical expertise.

Financial support: This study was supported by the Ministry of Education, Science, Culture and Sports of Japan (Grants 14256004, 18256004, and 18780230).

Authors' addresses: Hirotomo Kato, Yoshimi Terayama, and Hiroyuki Iwata, Department of Veterinary Hygiene, Faculty of Agriculture, Yamaguchi University, 1677-1 Yoshida, Yamaguchi 7538515, Japan. Hiroshi Uezato, Department of Dermatology, Faculty of Medicine, University of the Ryukyus, Nishihara, Okinawa 903-0215, Japan. Eduardo A. Gomez, Department of Epidemiology and Parasitology, National Institute of Health and Tropical Medicine, Guayaquil, Ecuador. Manuel Calvopiña and Yoshihisa Hashiguchi, Department of Parasitology, Kochi Medical School, Kochi University, Nankoku, Kochi 783-8505, Japan.

Reprint requests: Hirotomo Kato, Department of Veterinary Hygiene, Faculty of Agriculture, Yamaguchi University, 1677-1 Yoshida, Yamaguchi 753-8515, Japan, E-mail: katoh@yamaguchi-u.ac.jp.

\section{REFERENCES}

1. Desjeux P, 1996. Leishmaniasis. Public health aspects and control. Clin Dermatol 14: 417-423.

2. Choi CM, Lerner EA, 2001. Leishmaniasis as an emerging infection. J Invest Dermatol Symp Proc 6: 175-182.

3. Munstermann LE, 2004. Phlebotomine sand flies, the Psychodidae. Marquardt WC, Black WC, Freier JE, Hagedorn HH, Hemingway J, Higgs S, James AA, Kondratieff B, Moore CG, eds. Biology of Disease Vectors. Second edition. San Diego, CA: Elsevier, 141-151.

4. Hashiguchi Y, Gomez EAL, 1991. A review of leishmaniasis in Ecuador. Bull Pan Am Hlth Org 25: 64-76.

5. Hashiguchi Y, 2003. Leishmaniasis. Otsuru M, Kamegai S, Hayashi S, eds. Progress of Medical Parasitology in Japan. Tokyo: Megro Parasitological Museum, vol. 7. 537-553.

6. Dujardin J, Victoir CK, De Doncker S, Guerbouj S, Arevalo J, Le Ray D, 2002. Molecular epidemiology and diagnosis of Leishmania: what have we learnt from genome structure, dynamics and function? Trans R Soc Trop Med Hyg 96: S81-S86.

7. Vega-Lopez F, 2003. Diagnosis of cutaneous leishmaniasis. Curr Opin Infect Dis 16: 97-101.

8. Reithinger R, Dujardin JC, 2007. Molecular diagnosis of leish- maniasis: current status and future applications. J Clin Microbiol 45: 21-25.

9. Kato H, Uezato H, Katakura K, Calvopiña M, Marco JD, Barroso PA, Gomez EA, Mimori $\mathrm{T}$, Korenaga M, Iwata $\mathrm{H}$, Nonaka S, Hashiguchi Y, 2005. Detection and identification of Leishmania species within naturally infected sand flies in the Andean areas of Ecuador by a polymerase chain reaction. $A m$ J Trop Med Hyg 72: 87-93.

10. Calvopiña M, Armijos RX, Hashiguchi Y, 2004. Epidemiology of leishmaniasis in Ecuador: Current status of knowledge-a review. Mem Inst Oswaldo Cruz 99: 663-672.

11. Calvopiña M, Armijos RX, Marco JD, Uezato H, Kato H, Gomez EAL, Korenaga M, Barroso PA, Mimori T, Cooper PJ, Nonaka S, Hashiguchi Y, 2006. Leishmania isoenzyme polymorphisms in Ecuador: relationships with geographic distribution and clinical presentation. BMC Infect Dis 6: 139 .

12. Barroso PA, Marco JD, Kato H, Tarama R, Rueda P, Cajal SP, Basombrio MA, Korenaga M, Taranto NJ, Hashiguchi Y, 2007. The identification of sandfly species, from an area of Argentina with endemic leishmaniasis, by the PCR-based analysis of the gene coding for $18 \mathrm{~S}$ ribosomal RNA. Ann Trop Med Parasitol 101: 247-253.

13. Terayama $\mathrm{Y}$, Kato $\mathrm{H}$, Gomez EAL, Uezato $\mathrm{H}$, Calvopiña M, Iwata H, Hashiguchi Y, 2007. Molecular typing of sand fly species from areas endemic for leishmaniasis in Ecuador by PCR-RFLP of $18 S$ ribosomal RNA gene. (submitted).

14. Luyo-Acero G, Uezato H, Oshiro M, Kariya K, Katakura K, Gomez EAL, Hashiguchi Y, Nonaka S, 2004. Sequence variation of the cytochrome $b$ gene of various human patholgenic members of the genus Leishmania: a new approach for their identification. Parasitology 128: 483-491.

15. Thompson JD, Higgins DG, Gibson TJ, 1994. CLUSTAL W: improving the sensitivity of progressive multiple sequence alignment through sequence weighting, position-specific gap penalties and weight matrix choice. Nucleic Acids Res 22: 4673-4680.

16. Kumar S, Tamura K, Nei M, 2004. MEGA3: Integrated software for molecular evolutionary genetics analysis and sequence alignment. Brief Bioinform 5: 150-163.

17. Marco JD, Bhutto AM, Soomro FR, Baloch JH, Barroso PA, Kato H, Uezato H, Katakura K, Korenaga M, Nonaka S, Hashiguchi Y, 2006a. Multilocus enzyme electrophoresis and cytochrome $b$ gene sequencing-based identification of Leishmania isolates from different foci of cutaneous leishmaniasis in Pakistan. Am J Trop Med Hyg 75: 261-266.

18. Marco JD, Uezato H, Mimori T, Barroso PA, Korenaga M, Nonaka S, Basombrio MA, Taranto NJ, Hashiguchi Y, 2006b. Are cytochrome $b$ gene sequencing and polymorphism-specific polymerase chain reaction as reliable as multilocus enzyme electrophoresis for identifying Leishmania spp. from Argentina? Am J Trop Med Hyg 75: 256-260.

19. Cordoba-Lanus E, De Grosso ML, Pinero JE, Valladares B, Salomon OD, 2006. Natural infection of Lutzomyia neivai with Leishmania spp. in northwestern Argentina. Acta Trop 98: 1-5.

20. Cupolillo E, Medina-Acosta E, Noyes H, Momen H, Grimaldi G $\mathrm{Jr}, 2000$. A revised classification for Leishmania and Endotrypanum. Parasitol Today 16: 142-144.

21. Katakura K, Mimori T, Furuya M, Uezato H, Nonaka S, Okamoto M, Gomez LEA, Hashiguchi Y, 2003. Identification of Endotrypanum species from a sloth, a squirrel and Lutzomyia sandflies in Ecuador by PCR amplification and sequencing of the mini-exon gene. J Vet Med Sci 65: 649-653.

22. Rotureau B, Ravel C, Couppie P, Pratlong F, Nacher M, Dedet JP, Carme B, 2006. Use of PCR-restriction fragment length polymorphism analysis to identify the main New World Leishmania species and analyze their taxonomic properties and polymorphism by application of the assay to clinical samples. $J$ Clin Microbiol 44: 459-467. 